Contents list available at IJRED website

Int. Journal of Renewable Energy Development (IJRED)

Journal homepage: https://ijred.undip.ac.id

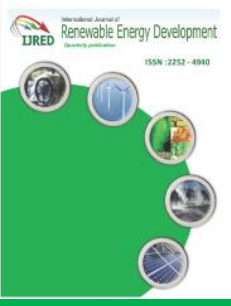

\title{
Techno-Economic Analysis of Wind Turbines Powering Rural of Malaysia
}

\author{
Ali Wadi Al-Fatlawi ${ }^{a^{*}}$, Maher A. R. Sadiq Al-Baghdadia, Hussein Togun ${ }^{b}$, \\ Goodarz Ahmadic, Saidur Rahman ${ }^{\text {, }}$, Nasrudin Abd Rahime \\ $a^{*}$ Department of Mechanical Engineering, University of Kufa Najaf, Iraq \\ ${ }^{b}$ Department of Mechanical Engineering, University of Thi-Qar, Nassiriya, Iraq \\ c Department of Mechanical and Aeronautical Engineering, Clarkson University, Potsdam, NY 13699-5725, USA \\ ${ }^{d}$ Centre for Nano-Materials and Energy Technology (RCNMET), Sunway University, Kuala Lumpur, Malaysia \\ e Power Energy Dedicated Advanced Centre (UMPEDAC), University of Malaya, Kuala Lumpur, Malaysia
}

\begin{abstract}
The purpose of this study is to evaluate the wind energy potential and energy cost of various types of wind turbines that could be powering rural Areas. The analysis was performed on hourly wind data over three years for five locations measured with a $10 \mathrm{~m}$-high anemometer in Peninsular Malaysia. The performance of wind turbines with varying hub heights and rated power was examined. The economic evaluation of wind energy in all sites was based on an analysis of the annual Levelized cost of energy. Results show that the annual mean wind speeds vary from $1.16 \mathrm{~m} / \mathrm{s}$ in Sitiswan to $2.9 \mathrm{~m} / \mathrm{s}$ in Mersing, whereas annual power varies from 3.6 to $51.4 \mathrm{~W} / \mathrm{m}^{2}$. Moreover, the results show that the cost of unit energy varies between (4.5-0.38) $\$ / \mathrm{kWh}$. The most viable site for the use of wind turbines was Mersing, while Sitiawan was the least viable site. A case study examined three wind turbine models operating at Mersing. The study showed that increasing the inflation escalation rate for operating and maintenance from $0-5 \%$ led to a decrease in the unit energy cost by about $38 \%$. However, increasing the operating and maintenance escalation rate from $0-10 \%$ led to an increase in the unit cost of energy by about $7-8 \%$.
\end{abstract}

Keywords: renewable energy, rural area, wind speed, economic analysis, wind turbine.

Article history: Received: $5^{\text {th }}$ Dec 2021; Revised: $6^{\text {th }}$ January 2022; Accepted: $10^{\text {th }}$ January 2022; Available online: $22^{\text {nd }}$ January 2022

How to cite this article: Al-Fatlawi, A.W.A., Al-Baghdadi, MARS., Togun, H., Goodarzd, A., Rahman, S., Rahim, N.A. (2022) Techno-economic Analysis of Wind Turbines Powering Rural of Malaysia. International Journal of Renewable Energy Development, 11(2), 413-421 https://doi.org/10.14710/ijred.2022.43477

\section{Introduction}

A stable and secure energy supply is essential for modern societies, especially in a rural area, where transmission lines may not have been designed to transport large amounts of energy. The energy demands in remote or rural areas pose particular challenges. The costs of installing an electric grid (including cables, transformers, towers, etc.) in these areas can be prohibitive, especially if the residents are spread over a vast area. Malaysia has a poverty rate of $3.8 \%$, which is mostly concentrated in rural areas (Borhanazad et al., 2013). These people depend on traditional fuels such as dung, wood, or agricultural residues. Many of these types of fuels cause serious health and environmental pollution problems. This is an enormous challenge that will require integrating noncarbon-based energy resources (e.g., wind energy, solar energy, etc.) with traditional sources (Al-fatlawi. et al., 2014).

Wind energy is the property of location, and among the main tools used in literature are the wind speed probability distributions and the function representations of these distributions. They are used for a variety of purposes and applications, from identifying the parameters of distribution functions to analyzing wind speed data and wind energy economics (Keyhani et al., 2010). It is estimated that the first statistical studies of wind speed began before 50 years ago, using the Gamma distribution (Sherlock, 1951). During this period, different distribution functions of wind speed have been proposed (Corotis et al., 1978; Conradsen et al., 1984), among them Pearson, Chi-2, Weibull, Rayleigh, and Johnson functions. Several non-normal distributions have been suggested as appropriate models for wind speed (inverse Gaussian distribution (Bardsley, 1980), log-normal distribution (Luna \& Church, 1974), Weibull distribution (Tchinda, \& Kaptouom, 2003; Keyhani et al., 2010; Adaramola, 2010 Islam et al., 2011; Hashemi et al., 2016; Mohammed et al., 2019), and squared normal distribution (Carlin \& Haslett, 1982). Among these functions, the Weibull distribution is commonly used in several different applications.

\footnotetext{
*Corresponding author: aliw.alfatlawi@uokufa.edu.iq
} 
A few wind energy studies were performed in Malaysia in recent years. These studies were generally focused on the availability and characteristics of the seasonal wind patterns at different locations throughout Peninsular Malaysia. Exell et al. studied wind energy potential in Malaysia. A total of 20 meteorological stations in Malaysia have used routine observations to determine the diurnal and seasonal variations of the wind. There are only a few stations along the east coast and in the south of West Malaysia where the annual mean wind power is over 20 $\mathrm{W} / \mathrm{m}^{2}$ during the northeast monsoon season between November and March. There is a wide range of estimates of the power density at $600 \mathrm{~m}$ above the surface, ranging from below $100 \mathrm{~W} / \mathrm{m}^{2}$ to over $300 \mathrm{~W} / \mathrm{m}^{2}$, especially along the east coasts of East and West Malaysia, particularly during the northeast monsoon (Exell et al., 1986).

Weibull distribution function used by Islam et al. to evaluate potential wind energy sites at Kudat and Labuan, Malaysia. The study found that wind speed power is insufficient to generate large amounts of electricity. Nevertheless, wind energy can be beneficial (Islam et al., 2011). In the same year, researcher Islam et al. developed a second study for the assessment of wind energy potential mapping for peninsular Malaysia in 2011. Input data included geographical parameters (latitude, longitude, and altitude), while output data included the monthly and yearly mean wind speeds. Compared to other parts of Peninsular Malaysia, the southern region is windy (Islam et al., 2011). Masseran et al. assessed the wind speed persistence for several wind stations in Peninsular Malaysia using hourly data collected at 10 wind stations from 2007 to 2009. Based on Levene's test of equality of variance, the wind speed variability between stations differs significantly. Chuping has the smallest variance of hourly wind speeds, so the wind speed observed at this location is most consistent. As a result, the wind speed at Mersing is the strongest, and as a result, this location has the most potential for energy production compared to other locations (Masseran et al., 2012). A study by Sopian et al. examined the wind energy potential in Malaysia. The wind data collected at ten stations in Malaysia were analyzed for wind energy potential. During the ten years (19821991), data were collected. Analysis indicated that the station at Mersing has the greatest potential, with a mean power density of $85.61 \mathrm{~W} / \mathrm{m}^{2}$ at $10 \mathrm{~m}$ above sea level (Sopian et al., 1995). Using reliability indices, Ali-Kadhem et al. assessed wind energy generation at specific sites in a peninsula in Malaysia by combining between Sequential Monte Carlo Simulation (SMCS) model and the Weibull distribution model to illustrate the role of wind power. For this purpose, Roy Billinton Test System (RBTS) is used and tested using wind data from two sites in Peninsular Malaysia. The results showed that Mersing and Kudat were the best wind sites. (Kadhem et al., 2019).

From the author's knowledge that the studies were limited in Malaysia and focused mostly on the characteristics of wind energy and potential locations, but did not consider economic aspects which are necessary to force the future investments in this technology. Therefore, there is a strong need for an economic feasibility study of wind energy conversion systems (WECS). Based on existing results, government energy policies could be developed for sustainable industrial development in rural homes or remote areas that did not have electricity or even may not have transmission lines designed to transport large amounts of energy.

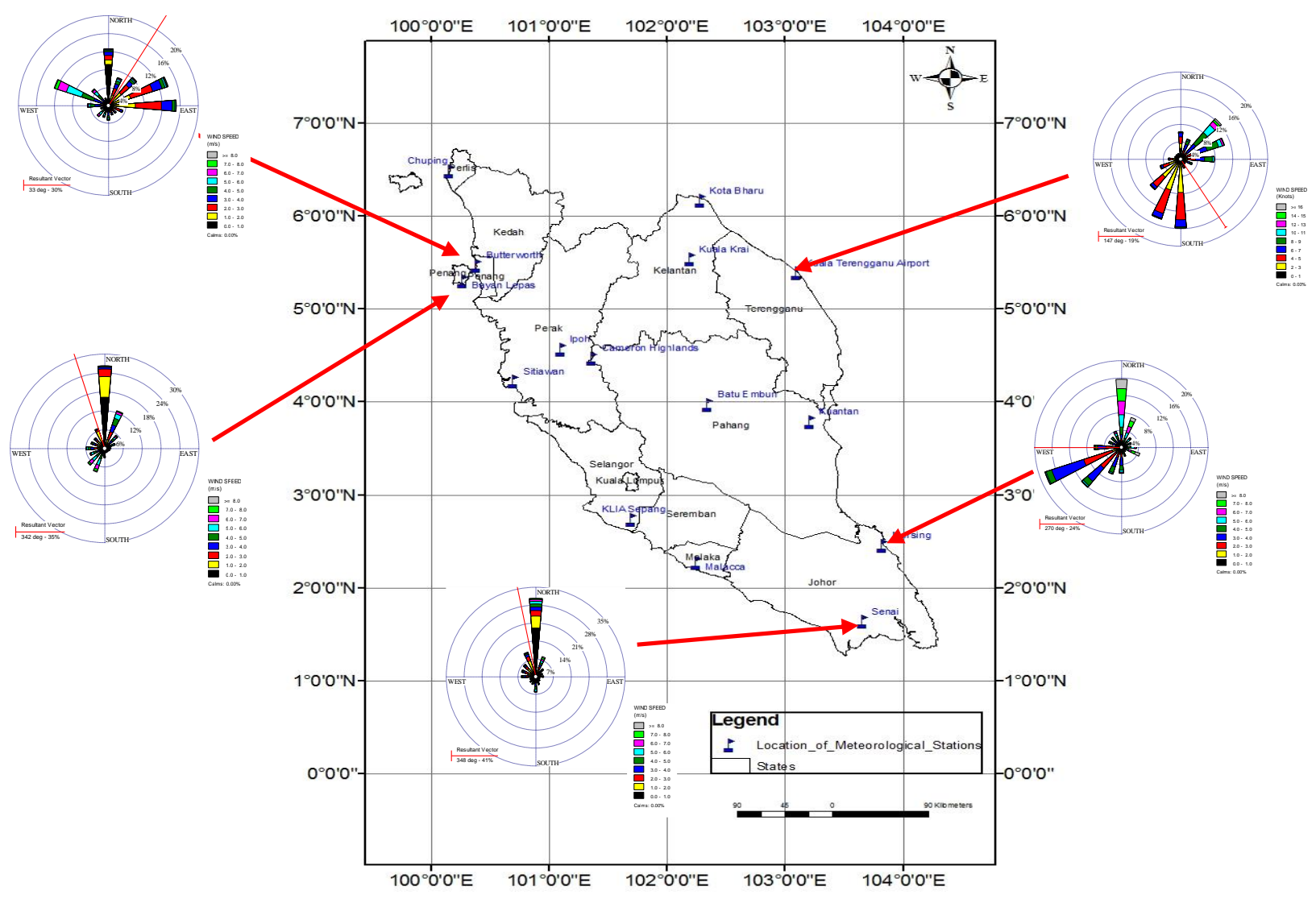

Fig 1. Geographical locations of the five selected stations 
Table 1

The geographical locations of the selected sites.

\begin{tabular}{clccc}
\hline \multirow{2}{*}{ Code } & Station & $\begin{array}{c}\text { Longitude } \\
(\mathrm{N})\end{array}$ & $\begin{array}{c}\text { Latitude } \\
(\mathrm{E})\end{array}$ & $\begin{array}{c}\text { Altitude } \\
(\mathrm{m})\end{array}$ \\
\cline { 3 - 6 } & Name & $\begin{array}{c}\text { Degree, } \\
\text { Minutes }\end{array}$ & $\begin{array}{c}\text { Degree, } \\
\text { Minutes }\end{array}$ & Sea Level \\
\hline 48601 & Bayan Lepas & $100^{\circ} 16^{\prime}$ & $5^{\circ} 18^{\prime}$ & 2.46 \\
48602 & Butterworth & $100^{\circ} 23^{\prime}$ & $5^{\circ} 27^{\prime}$ & 3.33 \\
48620 & Sitiawan & $100^{\circ} 42^{\prime}$ & $4^{\circ} 13^{\prime}$ & 6.78 \\
48674 & Mersing & $103^{\circ} 50^{\prime}$ & $2^{\circ} 27^{\prime}$ & 43.6 \\
48679 & Senai & $103^{\circ} 40^{\prime}$ & $1^{\circ} 38^{\prime}$ & 37.8 \\
\hline
\end{tabular}

Source: Malaysian Meteorological Department (MMD)

\section{Study field and data collection}

The performance of a wind energy conversion system (WECS) strongly depends on the natural wind patterns that are specific to a particular location. Since the wind resource data (e.g., speed, direction, etc.) can significantly change rapidly at any location, it is important to collect hourly data to characterize the wind resources properly at a site. Peninsular Malaysia has 27 ground-based meteorological stations, managed by the Malaysian Meteorological Department (MMD), that acquire hourly wind data using a cup-generator anemometer (with $10 \mathrm{~m}$ hub height). In the present study, wind resource data at five different locations in Peninsular Malaysia were collected, compiled, and used to assess the economic feasibility of wind turbines to generate electrical power. The locations of these stations are shown in Figure 1 and also listed in Table 1.

\section{Analysis Procedure}

The objective of the analysis is to determine the expected electrical power that can be generated at different locations in Peninsular Malaysia. Each of these locations has different annual wind characteristics represented by a Weibull Probability Distribution Function (WPDF). Measured WPDF data from different sites are extrapolated to account for greater WECS turbine hub heights. Then an economic analysis is performed to determine the Levelized Cost of Energy (LCOE) of different WECS.

\subsection{Weibull probability density function (WPDF)}

Wind speed distribution data are often represented by Weibull Probability Distribution Functions (WPDF). WPDF gives a distribution curve that indicates the fraction of time a specific wind speed occurs at a site under investigation. Different studies have used it to analyze wind resources, such as; (Celik et al., 2003; Islam et al., 2011; Kadhem et al., 2019; Adaramola et al., 2011; Sen et al., 2012; Weisser et al., 2003; Carta et al., 2009).

The WPDF, symbolized by $\mathrm{F}(\mathrm{v})$, is given as,

$$
F(v)=\left(\frac{k}{c}\right)\left(\frac{v}{c}\right)^{k-1} \exp \left(-\left(\frac{v}{c}\right)^{k}\right)
$$

In Equation 1, the term $\mathrm{k}$ is known as the shape factor and is defined by the following equation:

$$
k=\left(\frac{\sigma}{\bar{v}}\right)^{-1.086}(1 \leq k \leq 10)
$$

The term $\mathrm{c}$ is called the scale factor and is defined as:

$$
c=\frac{\bar{v}}{\Gamma(1+1 / k)}
$$

Here $\Gamma()$ is the gamma function. The standard deviation $(\sigma)$ is calculated as,

$$
\sigma=\left(\frac{1}{m-1} \sum_{j=1}^{m}\left(v_{j}-\bar{v}\right)^{2}\right)^{1 / 2}
$$

The probable wind speed $\left(\mathrm{V}_{\mathrm{F}}\right)$ is the most frequent wind speed for a given wind probability distribution. For the WPDF, the probable wind speed is a function of the scale and shape parameter, and is given as,

$$
V_{F}=c\left(1-\frac{1}{k}\right)^{\frac{1}{k}}
$$

The wind speed that carries the maximum amount of wind energy $\left(\mathrm{V}_{\mathrm{E}}\right)$ can be calculated using (Keyhani et al., 2010; Jamil et al., 1995),

$$
V_{E}=c\left(1+\frac{2}{k}\right)^{\frac{1}{k}}
$$

\subsection{Extrapolated data to hub height}

Wind speed generally varies with height due to changes in atmospheric temperature and pressure. In wind turbine applications, the mathematical extrapolation of wind speed to different turbine hub heights is essential in assessing the regional resources available and predicting the WECS performance. Extrapolation is typically done using a power law, which is given as,

$$
v(z)=v_{a}\left(\frac{z}{z_{a}}\right)^{\alpha_{p}}
$$

In Equation 7, the exponent $\alpha_{\mathrm{p}}$ is a function that accounts for the local climatology, topography, terrain surface roughness (e.g., obstructions, buildings, foliage, etc.), environmental conditions, meteorological lapse rate, and weather stability (Şen et al., 2012).

Justus and Mikhail proposed an empirical modified power-law model. In their model, the $a_{p}$ exponent is given by (Justus\& Mikhail,1976),

$$
\alpha_{p}=\frac{1}{\ln \left(\frac{z_{g}}{z_{o}}\right)}-\left(\frac{0.088}{\left(1-0.088 \ln \left(\frac{z_{a}}{10}\right)\right)}\right) \ln \left(\frac{v_{a}}{6}\right)
$$

Here $\mathrm{zg}$ is the geometric mean height between the hub height $(\mathrm{zh})$ and the measured anemometer height $\left(\mathrm{z}_{\mathrm{a}}\right)$ given as,

$$
z_{g}=\left(z_{h} \times z_{a}\right)^{0.5}
$$


In Equation 8, the terrain surface roughness $\left(\mathrm{z}_{0}\right)$ is a measure of physical obstruction to the wind. This factor has a high impact on the wind velocity profile, so it is an important parameter.

The shape factor $(\mathrm{k})$ and scale factor (c) must also be extrapolated to a new height. This is because the MMD wind speed measurements were taken at anemometer height rather than the height of the wind turbine hub. The scale factor extrapolation is given as (Justus et al., 1978)

$$
c(z)=c_{a}\left(\frac{z_{h}}{z_{a}}\right)^{\varepsilon}
$$

where the exponent $(\varepsilon)$ is given by;

$$
\varepsilon=\frac{\left[0.37-0.088 \ln \left(c_{a}\right)\right]}{1-0.088 \ln \left(\frac{z_{h}}{10}\right)}
$$

The extrapolated shape factor is

$$
k(z)=k_{a}\left(\frac{1-0.088 \ln \left(\frac{z_{a}}{10}\right)}{1-0.088 \ln \left(\frac{z_{h}}{10}\right)}\right)
$$

\subsection{Power calculations}

The wind power density is defined as the kinetic energy flux of wind velocity, and for the Weibull distribution is given as (Celik, 2004),

$$
\frac{P_{\text {wind }}}{A}=\frac{1}{2} \rho c^{3} \Gamma\left(\frac{k+3}{k}\right)
$$

Area (A) specified in Equation 13 is the circular area swept by the rotating turbine.

The power output curve of the WECS is controlled by three velocities: cut-in, cut-off, and rated velocities. The turbine can produce power when the wind speed rises above its rated cut-in speed $\left(\mathrm{V}_{c}\right)$. As the wind speed increases, the output power $\left(\mathrm{P}_{\text {out }}\right)$ also increases until the maximum average power is achieved, which is called the rated power $\left(\mathrm{P}_{\text {rated }}\right)$. The wind speed needed to produce this is called the rated velocity $\left(\mathrm{V}_{\mathrm{r}}\right)$. As wind speed further increases, it reaches a maximum cut-off velocity $\left(\mathrm{V}_{\mathrm{f}}\right)$, when the wind turbine is shut down to prevent the turbine from being damaged. These velocities are customized for a WECS design based on the wind characteristics of the site used.

The mean power output from WECS can be calculated based on WPDF parameters and design speeds. That is (Torres et al., 2003; Akpinar et al., 2005; Adaramola et al., 2011),

$$
P_{\text {out }}=P_{\text {rated }}\left(\frac{e^{-\left(\frac{v_{c}}{c}\right)^{k}}-e^{-\left(\frac{v_{r}}{c}\right)^{k}}}{\left(\frac{v_{r}}{c}\right)^{k}-\left(\frac{v_{c}}{c}\right)^{k}}-e^{-\left(\frac{v_{f}}{c}\right)^{k}}\right)
$$

Table 2

Design characteristics of WECS studied.

\begin{tabular}{llll}
\hline Wind Turbine Model & WT6000 & WT15000 & P10-20 \\
\hline Rated Power (kW) & 6 & 15 & 20 \\
Hub Height (m) & 15 & 36.6 & 36.6 \\
Rotor Diameter & 5.5 & 9 & 10 \\
Rated Wind Speed & 12 & 12 & 10 \\
Cut-in Wind Speed & 2.5 & 2.5 & 2.5 \\
Cut-out Wind Speed & - & - & 25 \\
Survival Speed & 65 & 65 & 59 \\
Weight (kg) & 500 & 1,100 & 1,725 \\
\hline Wind Turbine Model & P15-50 & P17-50 & P19-100 \\
\hline Rated Power (kW) & 50 & 53 & 100 \\
Hub Height (m) & 36.6 & 36.6 & 60 \\
Rotor Diameter & 15 & 16.5 & 19.1 \\
Rated Wind Speed & 10 & 11 & 12 \\
Cut-in Wind Speed & 2.5 & 2.7 & 2.5 \\
Cut-out Wind Speed & 25 & 25 & 25 \\
Survival Speed & 59 & 59 & 59 \\
Weight (kg) & 6,443 & 6,443 & 7,414 \\
\hline
\end{tabular}

Source: (Armanda et al., 2011)

The capacity factor $\left(\mathrm{C}_{\mathrm{f}}\right)$ is simply the ratio of output power over the rated power. That is,

$$
C_{f}=\frac{P_{\text {out }}}{P_{\text {rated }}}=\left(\frac{e^{-\left(\frac{v_{c}}{c}\right)^{k}}-e^{-\left(\frac{v_{r}}{c}\right)^{k}}}{\left(\frac{v_{r}}{c}\right)^{k}-\left(\frac{v_{c}}{c}\right)^{k}}-e^{-\left(\frac{v_{f}}{c}\right)^{k}}\right)
$$

Equation 15 shows that the capacity factor $\left(\mathrm{C}_{\mathrm{f}}\right)$ is a function of the shape (k) and scale (c) factors at the hub height of the wind turbine, as well as the WECS cut-in $\left(V_{c}\right)$, rated $\left(V_{r}\right)$, and cut-off $\left(V_{f}\right)$ wind speeds.

In the present study, the expected output power of existing WECS was calculated using the wind data collected at different Peninsular Malaysian sites. Table 2 shows the characteristics of the six models considered: WT6000 and WT15000 by Proven Wind Turbines (UK); and P10-20, P15-50, P17-50, and P19-100 built by Polaris (US) (Polaris American, 2012).

\subsection{Economics Analysis}

The economic feasibility of any WECS device is determined by its ability to generate electrical power at minimal operating cost rates. The three rates usually considered are the cost per rated turbine power, the cost per unit rotor size, and the cost per total electrical power $(\mathrm{kWh})$ generated (Martínez et al., 2009).

Another useful economic indicator is the Levelized Cost of Energy (LCOE), which is simply the metric that sums the lifetime cost of the energy system under consideration divided by the lifetime energy production to deliver output in cost per unit energy. Two estimations must be made to predict the LCOE of a project: the total annual investment cost of the system $\left(\mathrm{C}_{\text {Ann,total }}\right)$ and the total annual output power produced by the WECS ( $\mathrm{E}_{\text {syst,out }}$. LCOE (or unit cost of energy) is therefore defined by the following expression (Aldersey \& Williams, 2019),

$$
L C O E=\frac{C_{\text {Ann,total }}}{E_{\text {syst,out }}} \quad \text { Cost } / K W h
$$


The total annualized output power ( $\left.\mathrm{E}_{\text {syst,out }}\right)$ is equal to the sum of the power served, saved, and sold (feed-in tariff). The annual energy produced by the system can be estimated by multiplying the number of hours per year (8760) by the output power. That is:

$$
E_{\text {out }}=8760 P_{\text {rated }} C_{f}
$$

The net present cost of any system is equal to the sum of the total fixed and variable costs. The total fixed cost is equal to the amount invested. The variable cost consists of expenses for operation and maintenance (O\&M). Therefore, the variable cost depends on the WECS ongoing operating costs through its lifespan and its reliability (e.g., wear and tear).

The total annualized cost of the system can be estimated by multiplying the net present cost of the WECS (over its lifetime) by the capital recovery factor (Gökçek \& Genç, 2009),

$$
C_{\text {Ann,Total }}=\operatorname{CRF}\left(C_{\text {Cap }}+\lambda C_{o \& m}-C_{\text {Salv }}\right)
$$

Equation 18 shows that the total annualized cost is a function of the capital recovery factor (CRF), capital investment cost $\left(\mathrm{C}_{\mathrm{Cap}}\right)$, O\&M cost $\left(\mathrm{CO}_{\mathrm{O}} \mathrm{M}\right)$, salvage value $\left(\mathrm{C}_{\text {Salv }}\right)$, and discount rate $(\lambda)$. These are described in this section.

The capital recovery factor (CRF) is the present value of the cash flows through the system lifespan. CRF is a function of the interest rate and project lifespan (Hiendro et al., 2013), and determined by,

$$
C R F=\frac{r(1+r)^{n}}{(1+r)^{n}-1}
$$

The capital investment cost $\left(\mathrm{C}_{\mathrm{Cap}}\right)$ is the summation of the WECS cost $\left(\mathrm{C}_{\mathrm{Wind}, \mathrm{T}}\right)$, civil work construction cost $\left(\mathrm{C}_{\text {Civil, }}\right)$, connections cost $\left(\mathrm{C}_{\mathrm{Conn}, \mathrm{C}}\right)$, and miscellaneous components costs (CMisc,C) (e.g., control panels, electrical inverters, etc.). That is,

$$
C_{\text {Cap }}=C_{\text {Wind }, T}+C_{\text {Civil,C }}+C_{\text {Conn }, C}+C_{\text {Misc }, C}
$$

The share of each component for the cost breakdown of a typical onshore wind farm is presented in Figure 2 (Gökçek $\&$ Genç, 2009). This breakdown is used in the project cost analysis in this study.

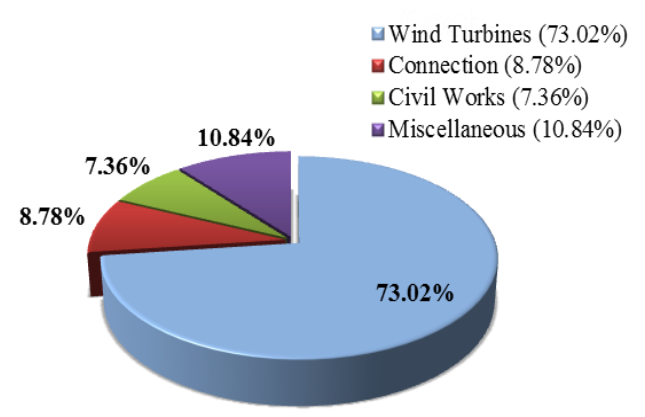

Fig. 2 Cost percentages of an on-shore wind farm.
Table 3

Capital and O\&M cost of wind turbine based on wind turbine size

\begin{tabular}{lcc}
\hline $\begin{array}{c}\text { Turbine size } \\
(\mathbf{k W})\end{array}$ & $\begin{array}{c}\text { Specific cost } \\
(\mathbf{\$} / \mathbf{k W})\end{array}$ & $\begin{array}{c}\text { Mean } \\
\text { Specific cost } \\
\mathbf{( \$ / k W )}\end{array}$ \\
\hline Less $20 \mathrm{~kW}$ & $2,200-3,000$ & 2,600 \\
$20-200 \mathrm{~kW}$ & $1,250-2,300$ & 1,775 \\
More $200 \mathrm{~kW}$ & $700-1,600$ & 1,150 \\
\hline
\end{tabular}

Source: (Armanda et al., 2011)

The discount rate $(\lambda)$ refers to the discount in cash flow throughout the project lifespan. This accounts for the fact that the current value of money is less than its future value because interest can be earned if the money is deposited in a bank. The discount rate is given by the following equation (Armanda et al., 2011).

$$
\lambda=\frac{1}{r-e_{o \& m}}\left(1-\left(\frac{1+e_{o \& m}}{1+r}\right)^{n}\right)
$$

Equation 21 shows that the discount rate $(\lambda)$ is a function of the operating and maintenance escalation rate $\left(\mathrm{e}_{o} \& \mathrm{~m}\right)$, the real interest rate (r), and the project lifespan (n). The real interest rate shows the actual change in purchasing power from investment because it is adjusted for the time value of money and the risk (or uncertainty) of anticipation of future cash flow. The interest rate is given by,

$$
r=\frac{i+f}{1+f}
$$

Equation 22 shows that the real interest rate is a function of the inflation rate $(f)$, which represents a rise in the general level of prices of goods and services over some time, and the nominal interest rate $(i)$, which is approximately the rate that investor receives from the bank if deposit money.

However, with taking the impact of escalation rate $(e)$ of operation and maintenance through the project life span, then inflation rate $(f)$ in Equation 22 can be corrected for the escalation rate $(e)$ using the Irving Fisher equation; the corrected apparent inflation rate $(\bar{f})$ is given by (Armanda et al., 2011),

$$
\bar{f}=(1+e)(1+f)-1
$$

The operation and maintenance cost (Co\&M) is an essential issue in any WECS because wind turbine components (e.g., gearbox, blades, etc.) are prone to wear and tear throughout the device's lifespan. In economics analysis, the O\&M cost for the first year of project lifespan is a reference year. However, the changing value of O\&M through project lifespan appears in the discount rate, which is presented by Equation 21. Lastly, the salvage value $\left(\mathrm{C}_{\text {Salv }}\right)$ represents the junked sale value of the remaining components after the system lifespan expires.

\subsection{Assumptions in the Analysis}

The LCOE analysis of all wind-turbine models considered in this study is based on the following assumptions:

- The project lifetime is assumed to be 20 years, the typical lifespan of WECS (Polaris American, 2012). 
- The nominal interest rate (i) and inflation rate (f) were assumed to be $12 \%$ and $4 \%$, respectively. However, the escalation rate (e) was assumed to vary between $0 \%-5 \%$.

- The capital cost in the present study is the total of all the system component costs. This is about $27 \%$ of the total cost of the wind turbine (Figure 2)

- The cost per $\mathrm{kW}$ of the rated power of the selected WECS models considered is listed in Table 3.

- Over the lifetime of a new turbine, cost (Co\&M) was assumed to be 20-25 percent of the Levelized cost per $\mathrm{kWh}$ generated.

- The operating and maintenance escalation rate (e\&m) were assumed to vary between the ranges $0 \%$ to $10 \%$. Lastly, it assumed that each WECS produces the same power throughout the project's lifetime.

\section{Result and discussion}

Five selected sites were monitored for hourly wind properties over three years between 2007 and 2009. When comparing data from one year to another (between 2007 and 2010), the difference in wind speed patterns can be seen to be small. Since the difference is quite small, the data collected on the wind turbine models based on the previous years can be used for WECS feasibility analysis. These data were used to calculate the potential power and energy output from commercial WECS models at various hub heights. In the following subsections, you will find the results and analysis of this study.

\subsection{Characteristics of wind in Malaysia}

The Weibull $\mathrm{k}$ value sometimes called the Weibull shape factor, is a parameter that represents the breadth of wind speed distributions. When the $\mathrm{k}$ value is lower it means that wind speeds tend to vary over a wide range of $k$ values. In the same context, higher $\mathrm{k}$ values indicate narrower wind speed distributions. A location characterized by very gusty winds may have a shape factor $(\mathrm{k})$ value as low as 1.5, while a location characterized by steady winds (such as tropical trade wind environments) could have a shape factor (k) more than 3 or 4 . Weibull $\mathrm{k}$ value of 2 is typical for many wind scenarios. In the present work, the shapes factor of wind speed data shows values ranging between 1.03 in Sitiawan to 2.17 in Mersing (at a $10 \mathrm{~m}$ hub height). The annual mean wind speeds are $1.57 \mathrm{~m} / \mathrm{s}, 2.9 \mathrm{~m} / \mathrm{s}$, $1.16 \mathrm{~m} / \mathrm{s}, 1.91 \mathrm{~m} / \mathrm{s}$, and $2.06 \mathrm{~m} / \mathrm{s}$, respectively, for Senai, Mersing, Sitiawan, Bayan Lepas, and Butterworth. The power generation efficiency is improved at sites with an annual mean wind speed more than the design cut-in wind speed of the wind turbine. However, the most probable wind speed (most frequent) ranges from very law a value of $0.04 \mathrm{~m} / \mathrm{s}$ in Sitiawan to $2.46 \mathrm{~m} / \mathrm{s}$ in Mersing. Between all sites, the maximum annual wind speeds occurred at Mersing $(4.43 \mathrm{~m} / \mathrm{s})$ and Sitiawan $(3.32 \mathrm{~m} / \mathrm{s})$. However, the wind turbine generates power most efficiently at the design-rated wind speed, shown in Table 2. Thus, the best performance occurs when the design-rated wind speed is close to the annual wind speeds of the selected site. Therefore, the best wind turbine performance is expected at the Mersing site. Islam's study on characteristics of wind speed agrees with the first part of our analysis (Islam et al., 2011). Many rural areas have wells that provide water for irrigation. If one considers the latter fact, then the latter wind speed $(2.9 \mathrm{~m} / \mathrm{s})$ is necessary for pumping water. Therefore, Mersing could be a candidate area for wind energy development. However, these applications remain limited to water pumping and small-scale electricity production. Furthermore, a high density of wind power ensures sustainable energy production. As can be seen, dramatic annual changes in wind power density were found with maximum value $\left(51.4 \mathrm{~W} / \mathrm{m}^{2}\right.$ in Mersing) being 13.3 times of ( $3.86 \mathrm{~W} / \mathrm{m}^{2}$ in Sitiawan). The power densities were extrapolated for a $30 \mathrm{~m}$ hub height using Equations 10,11 , and 12 .

\subsection{Capacity factor and energy output of WECS}

In this study, six different scale WECS from two companies (Kingspan Wind Turbines and Polaris) were used to assess the annual energy production for the selected sites. The characteristics of the WECS are listed in Table 2.

It should be noted that the data in Table 2 is for various hub heights, which is according to the sizes of wind turbines. Therefore, the shape and scale factors were extrapolated from this data to account for the hub heights of WECS operating at the selected sites. Furthermore, the capacity factor and annual energy output were found based on the shape and scale factors for each site and each WECS as shown in Table 4.

A capacity factor is defined as the maximum possible energy output of a wind turbine, under continuous operation at its nameplate capacity during a relevant period, usually calculated over one year. Considering the capacity factor measures actual wind turbine production, it is unrelated to Betz's coefficient (approximately 59.3\%), which limits the amount of wind energy available for production. The capacity factors of the selected wind turbines for various sites are shown in Figure 3.

In general, the capacity factor of all wind-turbine models in the Mersin site is the highest among all locations. This is because that the shape and scale factor of Mersing is high compared to other sites. The Sitiawan site has the lowest capacity factors for WECS applications due to low wind resources. The model P19-100 has the highest value among the models considered for all sites except in Mersing, where the models $\mathrm{P} 15-50$ and $\mathrm{P} 10-20$ have the highest capacity factor values. This is because the P19-100 hub is the tallest among the models considered in this study. At the same time, the rated wind velocities of P1550 and P10-20 are less than P19-100. This points to an important conclusion: in design, reducing the rated wind speed of WECS is more effective than increasing the tower height (hub height) for harvesting wind power. Nevertheless, the capacity factors of wind turbine models, ranging between $1.8 \%$ to $14.3 \%$ in Sitiawan and Mersing, respectively, are less than the typical value for wind energy development, which usually is more than $25 \%$ (Jonathan et al., 2017).

\section{Table 4}

Annual wind characteristics, shape, and scale parameters of selected sites (10 m hub height).

\begin{tabular}{llllll}
\hline Location & $\begin{array}{l}V_{m} \\
(\mathrm{~m} / \mathrm{s})\end{array}$ & $\begin{array}{l}V_{f} \\
(\mathrm{~m} / \mathrm{s})\end{array}$ & $\begin{array}{l}V_{e} \\
(\mathrm{~m} / \mathrm{s})\end{array}$ & $\mathrm{k}$ & $\mathrm{c}$ \\
\hline Senai & 1.57 & 0.32 & 3.90 & 1.17 & 1.66 \\
Mersing & 2.90 & 2.46 & 4.43 & 2.17 & 3.28 \\
Sitiawan & 1.16 & 0.04 & 3.32 & 1.03 & 1.17 \\
Bayan Lepas & 1.91 & 0.68 & 4.22 & 1.31 & 2.07 \\
Butterworth & 2.06 & 1.27 & 3.77 & 1.62 & 2.30 \\
\hline
\end{tabular}




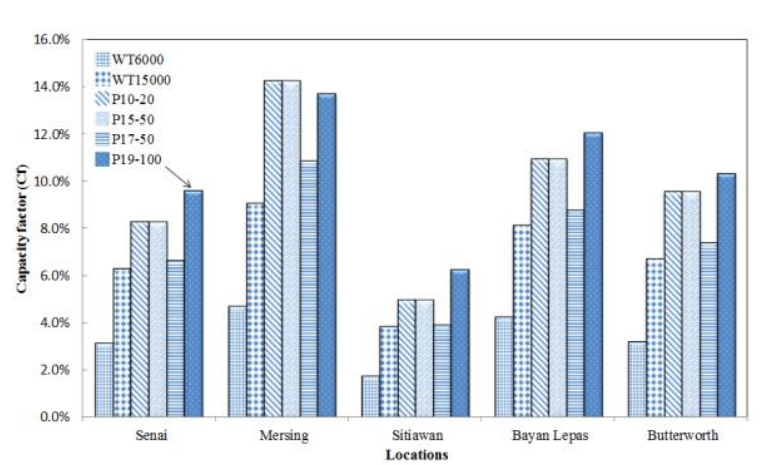

Fig. 3 Capacity factors of different WECS models for the selected sites.

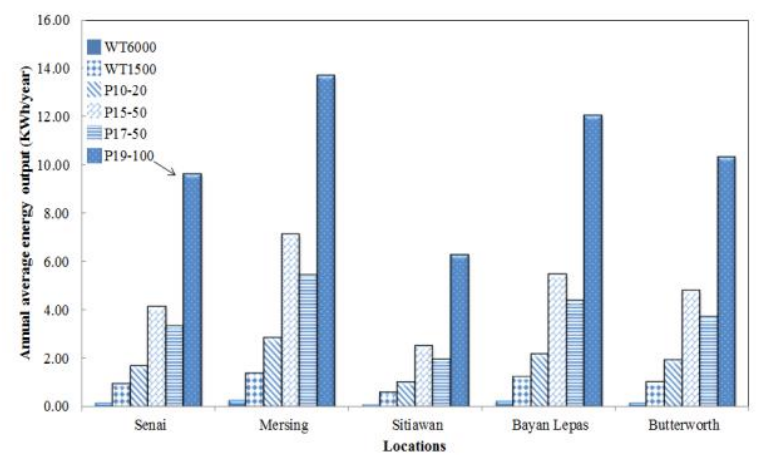

Fig. 4 Annual power output from the utilized WECS models for the selected sites.

The annual energy outputs of selected wind turbines are present in Figure 4. The range of annual energy output was from $13.7 \mathrm{kWh} /$ year in Mersing with the P19-100 model to $0.1 \mathrm{kWh} /$ year in Sitiawan using the WT6000 model. Figure 4 shows that among all sites used in the present study, Mersing city has the highest annual energy output for all WECS models considered in the present work. This is because of the high wind speeds in Mersing compared with other locations. Furthermore, the energy output of the P15-50 model is higher than the P17-50 Model. This is because cut-in wind speed and rated wind speed for the P15-50 model are less than P17-50. In general, the amount of energy output of the P19-100 model is the highest, while the energy output of WT6000 is the least because of the small hub height. Based on the amount of energy output of all types of WECS used in the present study, P19-100 represents the best choice for all locations considered in the current work.

\subsection{Cost of electric output}

The efficiencies of the electric output of all wind-turbine models are evaluated using the Levelized Cost of Energy (LCOE), which is the cost per $\mathrm{kWh}$ energy produced by wind turbine models. The Levelized cost of energy (LCOE), or cost of electricity, is an economic indicator that is used to determine the average net present cost of generating electricity for any wind turbine or generating plant. Consistently, it is used for investment planning and comparing different methods of electricity generation. Table 5 shows LCOE for all WECS models in all sites considered in the study. In this table, the influence of the effect of operating and maintenance and inflation rate are ignored. However, the effects of both operating and maintenance escalation rates and inflation rate on the unit cost of energy are evaluated and presented in Figures 5 and 6.

The best level cost of energy (LCOE) of all wind turbine models was found in the Mersing site, which has better wind characteristics than other sites. The lowest cost of unit energy (the lowest cost of wind energy) is obtained in Mersing using P10-20, P15-50, and P19-100 turbines, where the unit costs of energy are, respectively, 0.27, 0.27, and 0.28. However, for the highest cost of energy, it is seen that cost of energy varies between $0.51 \$ / \mathrm{kWh}$ by using P10-20 and P15-100 models in Mersing to 5.25 $\$ / \mathrm{kWh}$ in Sitiawan by using WT6000. This is because of the lowcapacity factors of all wind turbines in Sitiawan, leading to a low output power of all utilized models. This is particularly the case for the model, which has a small hub height such as WT6000.

Table 5

Cost of selected WECS $\$ / \mathrm{kWh}$.

\begin{tabular}{|c|c|c|c|c|}
\hline \multirow[t]{2}{*}{ Site } & \multirow[t]{2}{*}{ WECS } & \multicolumn{3}{|c|}{ LCOE } \\
\hline & & Min & Max & Mean \\
\hline \multirow{6}{*}{ 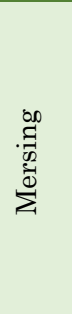 } & WT6000 & 1.44 & 1.70 & 1.96 \\
\hline & WT15000 & 0.75 & 0.88 & 1.02 \\
\hline & P10-20 & 0.27 & 0.56 & 0.49 \\
\hline & P15-50 & 0.27 & 0.38 & 0.49 \\
\hline & P17-50 & 0.35 & 0.50 & 0.65 \\
\hline & P19-100 & 0.28 & 0.40 & 0.51 \\
\hline \multirow{6}{*}{ 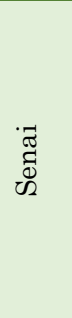 } & WT6000 & 2.14 & 2.53 & 2.92 \\
\hline & WT15000 & 1.07 & 1.26 & 1.46 \\
\hline & P10-20 & 0.46 & 0.96 & 0.85 \\
\hline & P15-50 & 0.46 & 0.65 & 0.85 \\
\hline & P17-50 & 0.58 & 0.82 & 1.06 \\
\hline & P19-100 & 0.40 & 0.57 & 0.73 \\
\hline \multirow{6}{*}{ 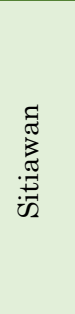 } & WT6000 & 3.85 & 4.55 & 5.25 \\
\hline & WT15000 & 1.74 & 2.05 & 2.37 \\
\hline & P10-20 & 0.76 & 1.59 & 1.41 \\
\hline & P15-50 & 0.76 & 1.09 & 1.41 \\
\hline & P17-50 & 0.97 & 1.38 & 1.78 \\
\hline & P19-100 & 0.61 & 0.87 & 1.13 \\
\hline \multirow{6}{*}{ 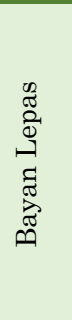 } & WT6000 & 1.59 & 1.88 & 2.17 \\
\hline & WT15000 & 0.83 & 0.98 & 1.13 \\
\hline & P10-20 & 0.35 & 0.73 & 0.64 \\
\hline & P15-50 & 0.35 & 0.50 & 0.64 \\
\hline & P17-50 & 0.44 & 0.62 & 0.80 \\
\hline & P19-100 & 0.32 & 0.45 & 0.59 \\
\hline \multirow{6}{*}{ 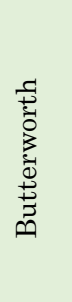 } & WT6000 & 2.09 & 2.47 & 2.85 \\
\hline & WT15000 & 1.01 & 1.19 & 1.37 \\
\hline & P10-20 & 0.40 & 0.83 & 0.74 \\
\hline & P15-50 & 0.40 & 0.57 & 0.74 \\
\hline & P17-50 & 0.52 & 0.73 & 0.95 \\
\hline & P19-100 & 0.37 & 0.53 & 0.68 \\
\hline
\end{tabular}




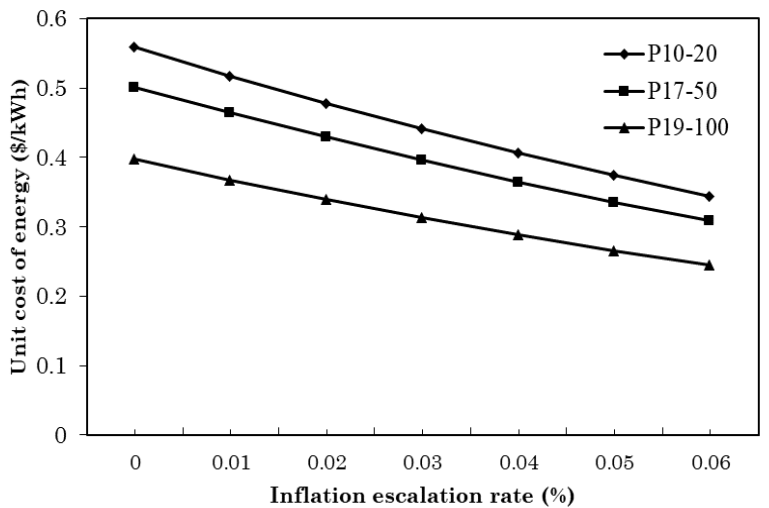

Fig. 5 Effect of inflation on the unit cost of energy for the Mersing site.

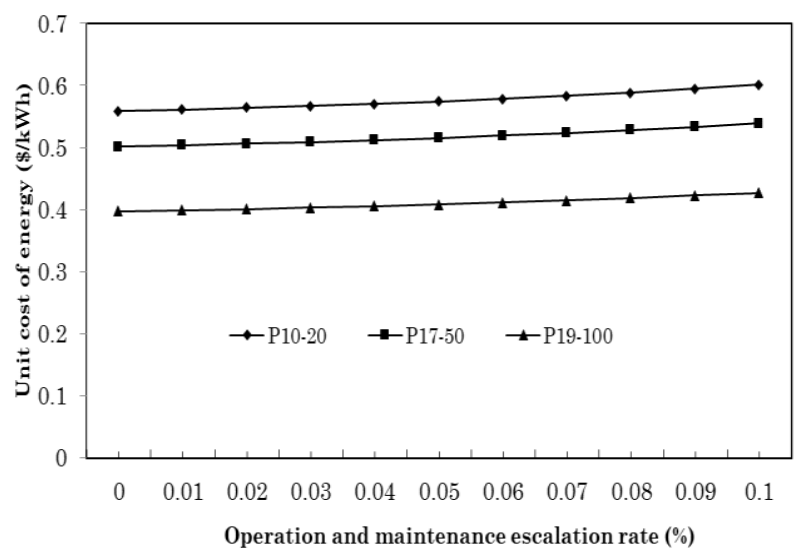

Fig. 6 Effect of O\&M escalation rate on the unit cost of energy for Mersing site.

From the current study based on the unit LCOE, we can infer that the better model for wind applications is P15-50 in Mersing. However, the overall unit cost of the windenergy system is still more than the current electricity cost of energy in Peninsular Malaysia. In Malaysia, the current range of electricity cost is $0.2-0.4 \mathrm{RM} / \mathrm{kWh}(0.065-0.13$ $\$ / \mathrm{kWh}$ ) proportionate with the amount of electricity consumption. Comparing the current electricity prices with WECS, we recommend that Malaysia's government use the scale models P10-20, P15-50, and P19-100 to provide electricity in remote areas in Mersing, even though the electricity cost is double. This is because of four important factors: First, the grid extension costs are saved when electricity is produced locally. Secondly, we used surplus energy. Thirdly: renewable energy saves the environment and contributes to the health of humanity and the future of our children. Fourthly, there is no guaranty of availability or the prices of oil in 50 years.

The impact of the increase in the inflation rate on the unit cost of energy for difference WECS is present in Figure 5. It is seen that augmenting the inflation of operating and maintenance costs decreases unit energy cost. The three selected models, P10-20, P17-50, and P19-100 show a decrease of about $38 \%$ with an increase of inflation from 0 $5 \%$, as shown in Figure 5. For the same condition, the discount rate factor decreased by $8 \%$. The graphical results are not shown here for brevity.

Figure 6 shows that the increase of operating and maintenance escalation rate $\left(e_{o \& m}\right)$ increases the unit cost of energy. By increasing $\left(e_{o \&}\right)$ from $0-10 \%$, the unit cost of energy increases by about $7-8 \%$ for the wind turbine models shown in Figure 6. Thus, it is inferred that an increase in the inflation escalation rate decreased the unit cost of energy while increasing the operating and maintenance escalation increased the unit cost of energy. These conclusions agree with the results of (Adaramola et $a l ., 2010)$ for their study in Nigeria region using similar commercial wind turbines.

\section{Conclusions}

A comprehensive study of the wind energy resources potential in five locations in Malaysia was performed. The performance and techno-economic analysis were based on the unit cost of energy of different commercial WECS in these locations.

The annual mean wind speeds are $1.57 \mathrm{~m} / \mathrm{s}, 2.9 \mathrm{~m} / \mathrm{s}$, $1.16 \mathrm{~m} / \mathrm{s}, 1.91 \mathrm{~m} / \mathrm{s}$, and $2.06 \mathrm{~m} / \mathrm{s}$, for Senai, Mersing, Setiawan, Bayan Lepas, and Butterworth respectively, and the respective annual mean power densities for these locations at anemometer height are $10.01 \mathrm{~W} / \mathrm{m}^{2}, 51.4$ $\mathrm{W} / \mathrm{m}^{2}, \quad 3.86 \mathrm{~W} / \mathrm{m}^{2}, \quad 17.99 \mathrm{~W} / \mathrm{m}^{2}$, and $21.12 \mathrm{~W} / \mathrm{m}^{2}$, respectively. The estimated capacity factors ranged from a minimum value of $1.8 \%$ (for the WT6000 model at Sitiawan) to a maximum value of $14.3 \%$ (for the P15-50 model at Mersing). The economic analysis showed that the lowest wind energy costs were at Mersing for the P10-20, P15-50, and P19-100 WECS. The unit costs of energy estimated using these WECS were, respectively, 0.27 $\$ / \mathrm{kWh}, 0.27 \$ / \mathrm{kWh}$, and $0.28 \$ / \mathrm{kWh}$.

An increase of the inflation escalation rate $(e)$ of operating and maintenance from $0-5 \%$ led to a decrease in the unit energy cost by about $38 \%$. While increasing the operating and maintenance escalation rate $\left(e_{0} \& m\right)$ from 0 $10 \%$ led to an increase in the unit cost of energy by about 7-8\% for the wind-turbine models P10-20, P17-50, and P19100.

Last not least, Malaysia has a complex topography, local conditions in a valley will also greatly affect wind speed and direction. Thus, attention should be paid to finding locations within Mersing valleys where these conditions exist.

\section{References}

Adaramola, M. S., Paul, S. S., \& Oyedepo, S. O. (2011). Assessment of electricity generation and energy cost of wind energy conversion systems in north-central Nigeria. Energy Conversion and Management, 52(12), 3363-3368; https://doi.org/10.1016/j.enconman.2011.07.007

Aldersey-Williams, J., Rubert, T. (2019). Levelised cost of energy - A theoretical justification and critical assessment, Energy Policy, 124

169-179; https://doi.org/10.1016/j.enpol.2018.10.004

Ali Kadhem, A., Abdul Wahab, N. I., \& N Abdalla, A. (2019). Wind energy generation assessment at specific sites in a Peninsula in Malaysia based on reliability indices. Processes, 7(7), 399.;https://doi.org/10.3390/pr7070399

Al-Fatlawi, A. W. A., Rahim, N. A., Saidur, R., \& Ward, T. A. (2015). Improving solar energy prediction in complex topography using artificial neural networks: Case study Peninsular Malaysia. Environmental Progress \& Sustainable Energy, $\quad 5(34), \quad$ 15281535.;https://doi.org/10.1002/ep.12130

Al-Fatlawi, A.W.A, Abdul-Hakim, S. R., Ward, T. A., \& Rahim, N. A. (2014). Technical and economic analysis of renewable energy powered stand-alone pole street lights for remote 
area. Environmental Progress \& Sustainable Energy, 33(1), 283-289.https://doi.org/10.1002/ep.11772

Akpinar, E. K., \& Akpinar, S. (2005). An assessment on seasonal analysis of wind energy characteristics and wind turbine characteristics. Energy conversion and management, 46(11$12)$, 1848-1867. https://doi.org/10.1016/j.enconman.2004.08.012

Bardsley, W. E. (1980). Note on the use of the inverse Gaussian distribution for wind energy applications. Journal of Applied Meteorology and Climatology, 19(9), 11261130.https://doi.org/10.1175/15200450(1980)019<1126:NOTUOT>2.0.CO;2

Borhanazad, H., Mekhilef, S., Saidur, R., \& Boroumandjazi, G. (2013). Potential application of renewable energy for rural electrification in Malaysia. Renewable energy, 59, 210219.https://doi.org/10.1016/j.renene.2013.03.039

Bosch, J., Staffell, I., Hawkes, A.D. (2017). Temporally-explicit and spatially-resolved global onshore wind energy potentials, Energy, $\quad 131 \quad$ 207-217. https://doi.org/10.1016/j.energy.2017.05.052

Carlin, J., \& Haslett, J. (1982). The probability distribution of wind power from a dispersed array of wind turbine generators. Journal of Applied Meteorology and Climatology, 21(3), 303-313.https://doi.org/10.1175/15200450(1982)021<0303:TPDOWP>2.0.CO;2

Carta, J. A., Ramirez, P., \& Velazquez, S. (2009). A review of wind speed probability distributions used in wind energy analysis: Case studies in the Canary Islands. Renewable and sustainable energy reviews, 13(5), 933955.https://doi.org/10.1016/j.rser.2008.05.005

Celik, A. N. (2003). Energy output estimation for small-scale wind power generators using Weibull-representative wind data. Journal of wind engineering and industrial aerodynamics, 91(5), 693-707. https://doi.org/10.1016/S01676105(02)00471-3

Celik, A. N. (2004). A statistical analysis of wind power density based on the Weibull and Rayleigh models at the southern region of Turkey. Renewable energy, 29(4), 593604.https://doi.org/10.1016/j.renene.2003.07.002

Conradsen, K., Nielsen, L. B., \& Prahm, L. P. (1984). Review of Weibull statistics for estimation of wind speed distributions. Journal of Applied Meteorology and Climatology, 23(8), 1173-1183.https://doi.org/10.1175/15200450(1984)023<1173:ROWSFE $>2.0 . \mathrm{CO} ; 2$

Corotis, R. B., Sigl, A. B., \& Klein, J. (1978). Probability models of wind velocity magnitude and persistence. Solar energy, 20(6), 483-493.https://doi.org/10.1016/0038-092X(78)900658

Exell, R. H. B., \& Fook, C. T. (1986). The wind energy potential of Malaysia. Solar Energy, 36(3), 281289.https://doi.org/10.1016/0038-092X(86)90143-X

Gökçek, M. and M.S. Genç (2009). Evaluation of electricity generation and energy cost of wind energy conversion systems (WECSs) in Central Turkey. Applied Energy, 86(12): $\quad$ p. 27312739.https://doi.org/10.1016/j.apenergy.2009.03.025

Hashemi-Tilehnoee, M., Babayani, D., \& Khaleghi, M. (2016). Evaluating wind energy potential in Gorgan-Iran using two methods of Weibull distribution function. International Journal of Renewable Energy Development, 5(1), 43.https://doi.org/10.14710/ijred.5.1.43-48

Hiendro, A., Kurnianto, R., Rajagukguk, M., \& Simanjuntak, Y. M. (2013). Techno-economic analysis of photovoltaic/wind hybrid system for onshore/remote area in Indonesia. Energy, 59, 652-657.https://doi.org/10.1016/j.energy.2013.06.005

Islam, M.R., Saidur, R. and Rahim, N.A. (2011). Assessment of wind energy potentiality at Kudat and Labuan, Malaysia using Weibull distribution function. Energy, 36(2): p. 985992.https://doi.org/10.1016/j.energy.2010.12.011
Islam, M. R. (2011). Assessment of wind energy potential mapping for peninsular Malaysia (Doctoral dissertation, Jabatan Kejuruteraan Mekanik, Fakulti Kejuruteraan, Universiti Malaya).

Jamil, M., Parsa, S., \& Majidi, M. (1995). Wind power statistics and an evaluation of wind energy density. Renewable energy, 6(5-6), 623-628.https://doi.org/10.1016/0960-1481(95)00041$\mathrm{H}$

Justus, C. G., \& Mikhail, A. (1976). Height variation of wind speed and wind distributions statistics. Geophysical Research Letters, $3(5)$, 261-264. https://doi.org/10.1029/GL003i005p00261

Justus, C. G., Hargraves, W. R., Mikhail, A., \& Graber, D. (1978). Methods for estimating wind speed frequency distributions. Journal of applied meteorology, 17(3), 350353.https://doi.org/10.1175/15200450(1978)017<0350:MFEWSF>2.0.CO;2

Keyhani, A., Ghasemi-Varnamkhasti, M., Khanali, M., \& Abbaszadeh, R. (2010). An assessment of wind energy potential as a power generation source in the capital of Iran, Tehran. Energy, 35(1), 188201.https://doi.org/10.1016/j.energy.2009.09.009

Luna, R. E., \& Church, H. W. (1974). Estimation of long-term concentrations using a "universal" wind speed distribution. Journal of Applied Meteorology and Climatology, 13(8), 910916.https://doi.org/10.1175/15200450(1974)013<0910:EOLTCU>2.0.CO;2

Masseran, N., Razali, A. M., Ibrahim, K., \& Zin, W. W. (2012). Evaluating the wind speed persistence for several wind stations in Peninsular Malaysia. Energy, 37(1), 649656.https://doi.org/10.1016/j.energy.2011.10.035

Martínez, E., Sanz, F., Pellegrini, S., Jiménez, E., \& Blanco, J. (2009). Life cycle assessment of a multi-megawatt wind turbine. Renewable energy, 34(3), 667673.https://doi.org/10.1016/j.renene.2008.05.020

Mohammed, D., Abdelaziz, M., Sidi, A., Mohammed, E., \& Elmostapha, E. (2019). Wind speed data and wind energy potential using Weibull distribution in Zagora, Morocco. International Journal of Renewable Energy Development, 8(3), 267-273.https://doi.org/10.14710/ijred.8.3.267-273

Polaris American. <http://www.polaris america.com/> [accessed 03.09.21].

Rieradevall, J., Domènech, X., \& Fullana, P. (1997). Application of life cycle assessment to landfilling. The International Journal of Life Cycle Assessment, 2(3), 141144.https://doi.org/10.1007/BF02978806

Şen, Z., Altunkaynak, A., \& Erdik, T. (2012). Wind velocity vertical extrapolation by extended power law. Advances in Meteorology, 2012.https://doi.org/10.1155/2012/178623

Sherlock, R. H. (1951). Analyzing winds for frequency and duration. In On Atmospheric Pollution (pp. 42-49). American Meteorological Society, Boston, MA.https://doi.org/10.1007/978-1-940033-03-79

Sopian, K., Othman, M. H., \& Wirsat, A. (1995). The wind energy potential of Malaysia. Renewable Energy, 6(8), 10051016.https://doi.org/10.1016/0960-1481(95)00004-8

Tchinda, R., \& Kaptouom, E. (2003). Wind energy in Adamaoua and North Cameroon provinces. Energy Conversion and Management, 44(6), 845-857.https://doi.org/10.1016/S01968904(02)00092-4

Torres, J. L., Prieto, E., Garcia, A., De Blas, M., Ramirez, F., \& De Francisco, A. (2003). Effects of the model selected for the power curve on the site effectiveness and the capacity factor of a pitch regulated wind turbine. Solar Energy, 74(2), 93102; https://doi.org/10.1016/S0038-092X(03)00144-0

Weisser, D. (2003). A wind energy analysis of Grenada: an estimation using the 'Weibull' density function. Renewable energy, 28(11), 1803-1812; https://doi.org/10.1016/S09601481(03)00016-8 